\title{
Tumoral Necrosis Factor (TNF) mRNA gene expression in relation to Vascular Endothelial Growth Factor (VEGF) and chemokines mRNA gene expression in tumoral microenvironment of endometrial cancer versus normal endometrium: Preliminary results
}

Giannice Raffaella ${ }^{1,2}$, Erreni Marco ${ }^{3}$, Gaetano Valenti ${ }^{1}$, Yael Hants ${ }^{1}$, Hooman Soleymani-Majid ${ }^{1}$, Riccardo Garruto-Campanile ${ }^{1}$, Mauro Felline $^{2}$, Paolo Guarnerio ${ }^{2}$, Allavena Paola ${ }^{3}$ and Tozzi Roberto ${ }^{1}$

${ }^{1}$ Department of Gynaecologic Oncology, Oxford University Hospital, Oxford UK

${ }^{2}$ Department of Gynaecologic and Obstetrics, ASST Santi Paolo e Carlo, Milan, Italy

${ }^{3}$ Immunology and Inflammation Department, IRCCS Humanitas, Via A. Manzoni 53, Rozzano, (MI) Italy

\begin{abstract}
Introduction: Tumor microenvironment inflammatory cells play a major role in cancer progression. Tumour Necrosis Factor (TNF) induces apoptosis in a variety of cancer cells playing a role in cancer growth and metastasis. Some chemokines and growth factors are related to TNF in many tumours. In this preliminary study we compared the TNF, VEGF, CXCL8, CXCL12, CXCL11 mRNA gene expression in normal endometrium (NE) versus endometrial cancer (EC) microenvironment.

Materials and methods: Fresh samples of EC tissue and NE were extracted from 15 patients with FIGO stage I-III undergoing primary surgery. Some of the tissue was sent for histology and part of it was treated with RNA later and stored at $-80^{\circ} \mathrm{C}$. RNA was reverse-transcribed, treated with DNase I, quantified and reversetranscribed into cDNA using random primers. A real-time quantitative PCR determined the relative cDNA levels of genes in each sample.

Results: We collected tissue samples from EC and from NE in 15 patients with endometrial cancer FIGO stage I-IIIC. Four patients dropped out. In the comparison between NE versus EC, we found down-regulation of TNF mRNA in 73\%, VEGF mRNA up-regulation in 54\%, CXCL12 down-regulation in 91\% of samples, down-regulation of CXCL11 of 54\% and CXCL8 up-regulation in 64\% of samples. Expression of TNF was significative directly related to the expression of CXCL12 $(\mathrm{P}=0.01)$ and of CXCL8 $(\mathrm{P}=0.05)$.
\end{abstract}

Conclusion: Directly statistically significant correlation found among downregulation of TNF, CXCL12 and CXCL8, seem to suggest a reduced ability of the host immune response against the cancer invasiveness and growth of the tumoral microenvironment. Unexpectedly, no significant correlation was found between VEGF and CXCL12, CXCL8 and CXCL11.We will expect from a further analysis on a greater sample size the definitive and more significant results.

\section{Introduction}

Tumour microenvironment inflammatory cells play a major role in cancer progression by the production of proteins mediators: chemokines, cytokines and growth factors. Among these mediators, Tumour Necrosis Factor (TNF) is a pro-inflammatory cytokine produced by activated macrophages and other cells of the tumour microenvironment, inducing apoptosis in a variety of cancer cell types playing a role in cancer growth and metastasis [1-3]. Physiologically, TNF is involved in the cyclic normal endometrial shedding and regeneration and TNF gene mRNA expression shows a specific menstrual cycledependent expression increased in the human normal endometrium in the late secretory phase and during endometrial bleeding $[4,5]$. Increased TNF serum concentration has been reported in patients with endometrial carcinoma and has been significantly related to a higher risk of endometrial cancer [6-8]. Some chemokines and growth factors are related to TNF in some tumors. CXCL8 is a chemokine related to invasiveness and neo-angiogenesis. In breast cancer cells the increased CXCL8 expression level reflects increased invasiveness into
Matrigel [9]. Conditioned media from such tumour cells also promoted angiogenesis in vivo when injected subcutaneously into nude mice [9]. CXCL8 is also constitutively expressed by many melanoma cell lines in vitro and it is mitogenic [10]. In lung tumour cells CXCL8 expression was dose-dependent increased by TNF and TNF inhibition with neutralizing antibodies reduced the CXCL8 expression [11]. In human ovarian cancer, tumour-associated plasmacytoid dendritic cells induced angiogenesis through production of TNF and CXCL8

*Correspondence to: Raffaella Giannice, Department of Gynaecologic Oncology, Children's and Women's Division, Oxford University Hospital, Old Road OX3 7LJ, Oxford, UK, Tel: 441865 235662; Fax: 441865235676; E-mail: raffaellagiannice@libero.it

Key words: endometrial cancer, tumoral microenvironment, tumour necrosis factor, vascular endothelial growth factor, CXCL8, CXCL11, CXCL12

Received: November 01, 2018; Accepted: November 19, 2018; Published: November 23, 2018 
Raffaella G (2018) Tumoral Necrosis Factor (TNF) mRNA gene expression in relation to Vascular Endothelial Growth Factor (VEGF) and chemokines mRNA gene expression in tumoral microenvironment of endometrial cancer versus normal endometrium: Preliminary results

[12]. Interestingly, in ovarian epithelial cancer cells VEGF induce neovascularization in the tumour microenvironment and stable silencing of TNF resulted in significantly low levels of VEGF [13-15]. CXCL11 is provided with angiostatic activity in response to VEGF in many cancers [17-19]. On the contrary, CXCL12 has been showed to promote angiogenesis [20]. Salcedo reported in normal human endothelial cells overexpression of VEGF induced by CXCL12 [21]. In this study we compared the expression of TNF, CXCL8, CXCL12, CXCL11 and VEGF gene expression in normal endometrium versus endometrial cancer microenvironment. This preliminary study represents just the first step of a larger protocol, designed to select the most relevant chemokines, cytokines or growth factors to analyse in each inflammatory cells subpopulation of endometrial tumoral microenvironment (granulocytes, macrophages, natural killer, fibroblasts, tumoral cells).

\section{Materials and methods}

Immediately after surgery, fresh samples of endometrial cancer (EC) and their normal endometrial counterpart (NE) were obtained from patients submitted to primary surgery for endometrial cancer at Humanitas Clinical Institute in Milan (Italy). Parts of the samples were used for the histologic diagnosis and other parts were immediately treated with RNA later (Ambion) for $24-36 \mathrm{~h}$ at $4^{\circ} \mathrm{C}$, and subsequently dried and stored at $-80^{\circ} \mathrm{C}$.

The study was approved by the Ethical Committee of Humanitas Research Institute and informed, written consent was obtained for all patients. All the clinical and surgical data were recorded on a database. The total RNA was isolated both from endometrial cancer and normal endometrial specimen using TRI Reagent (Ambion). RNA was quantified by Nanodrop spectrophotometer ND-1000 and its quality was examined by $1.5 \%$ agarose gel electrophoresis.

According to the manufacturer's instructions, $1 \mathrm{mg}$ of total RNA was reverse-transcribed using the High-Capacity cDNA Archive kit (Applied Biosystems), treated with DNase I, quantified and reversetranscribed into cDNA using random primers. A real-time quantitative polymerase chain reaction, using Syber Green I (Applied Biosystem) as detection dye, was used to determine the relative cDNA levels of genes in each sample. The amplification protocol was used as following: $2 \mathrm{~min}$ at $50^{\circ} \mathrm{C}$ to activate uracil-DNA glycosylase, $10 \mathrm{~min}$ at $94.5^{\circ} \mathrm{C}$ (activation), 40 cycles of denaturation al $97^{\circ} \mathrm{C}$ for $30 \mathrm{~s}$ and annealing and extension at $59.7^{\circ} \mathrm{C}$ for $1 \mathrm{~min}$. The relative amount of each target gene mRNA to the housekeeping gene (18S) was calculated as $2^{\text {(-DDCt)}}$, where $\mathrm{DCt}=\mathrm{Ct}$ gene $-\mathrm{Ct}$ housekeeping gene. The fold-change of each target gene mRNA to the corresponding normal tissue was calculated as $2^{(-\mathrm{DDC} t)}$, where DDCt=DCt target gene in tumour tissue - DCt target gene in normal tissue. The threshold cycle $\mathrm{Ct}$ was automatically given by the SDS2.2 software package (Applied Biosystems).

For preliminary results we analysed some genes usually involved in the tumour progression and angiogenesis: TNF, VEGF and CXCL8.

Statistical analysis: Statistical significance of proportion of samples with was determined by $\mathrm{T}$-test and considered significant at a $\mathrm{P}$ value of $<0.05$.

\section{Results}

We collected tissue samples from endometrial cancer (EC) and from normal corresponding endometrium (NE) in 15 patients with endometrial cancer FIGO stage I-IIIC. All patients were submitted to primary laparoscopic total hysterectomy and bilateral salpingooophorectomy with pelvic lymphadenectomy.
Four patients dropped out from the study: two because the endometrial sample was damaged during the storage, making it impossible to process, and two because no residual tumour was found in the samples, despite an initial histologic diagnosis by endometrial biopsy. In Tables 1 and 2 are described the patient's clinical characteristics.

A total of 11 samples were analysed. Patient's clinical characteristics are described in Tables 1 and 2. In the comparison between normal endometrium (NE) versus endometrial cancer (EC), we found $73 \%$ of patient with down-regulation of TNF mRNA (Figure 1), 54\% of patient with VEGF mRNA up-regulation (Figure 2), $91 \%$ of patient with CXCL12 mRNA down-regulation (Figure 3, p<0.01), 64\% of patients with up-regulation of CXCL8 mRNA (Figure 4) and 54\% of patients with CXCL11 mRNA down-regulation (Figure 5). Expression of TNF mRNA was significative directly related to the expression of CXCL12 mRNA in $81 \%$ of samples $(\mathrm{P}=0.01)$ and significative directly related with CXCL8 expression $(\mathrm{P}=0.05)$.

\section{Discussion}

In this preliminary study, TNF mRNA down-regulation was detected in $73 \%$ of samples of endometrial cancer compared with the normal counterpart. According to the TNF pro-apoptotic activity, this data seems to suggest a reduced ability of the host immune response against the cancer invasiveness and growth. This is also confirmed by the directly statistically significant correlation found among TNF, CXCL12 and CXCL8 mRNA all mediators involved in neoangiogenesis and tumour progression. Unexpectedly, no significant correlation was found between VEGF and the chemokines CXCL12, CXCL8 (involved in neoangiogenesis) and CXCL11 (with angiostatic activity).

Table 1. Clinical characteristics of patients with endometrial cancer

\begin{tabular}{|l|c|}
\hline No. of patients & 11 \\
\hline Median age (years) & 63 (range 53-81) \\
\hline Median BMI $\left(\mathrm{Kg} / \mathrm{m}^{2}\right)$ & 28 (range 25-31) \\
\hline FIGO stage & $8(73 \%)$ \\
I & $3(27 \%)$ \\
III & \\
\hline Histotype & $7(64 \%)$ \\
Endometrioid & $2(18 \%)$ \\
Clear cell & $1(9 \%)$ \\
Villoglandular & $1(9 \%)$ \\
Endometrioid with & \\
squamous differentiation & \\
\hline
\end{tabular}

BMI: Body Mass Index

Table 2. Patients chacteristics

\begin{tabular}{|c|c|c|c|c|c|c|c|}
\hline Patient & Age & $\begin{array}{c}\text { FIGO } \\
\text { stage }\end{array}$ & LVS & $\begin{array}{c}\text { Pelvic } \\
\text { Nodes }\end{array}$ & Grading & Histotype & $\begin{array}{c}\text { Adjuvant } \\
\text { therapy }\end{array}$ \\
\hline 1 & 66 & IA & - & - & G3 & EA & FU \\
\hline 2 & 65 & IA & - & - & G3 & CCA & PAC-RT \\
\hline 3 & 75 & IA & - & - & G1 & VA & FU \\
\hline 4 & 63 & IA & - & - & G2 & EA & FU \\
\hline 5 & 58 & IA & - & - & G2 & EA & FU \\
\hline 6 & 68 & IA & - & - & G2 & EA & FU \\
\hline 7 & 61 & IA & - & - & G2 & EA & FU \\
\hline 8 & 81 & IB & - & - & G2 & EA & FU \\
\hline 9 & 53 & IIIA & - & - & G2 & SA & PAC+EBRT \\
\hline 10 & 81 & IIIIA & + & - & G2 & CCA & CT+EBRT \\
\hline 11 & 63 & IIIC & + & + & G2 & EA & EBRT \\
\hline
\end{tabular}

LVS: Lymph vascular space; EA: Endometrioid adenocarcinoma; CCA: Clear cell adenocarcinoma; VA: Villoglandular adenocarcinoma; SA: Squamous adenocarcinoma; PAC: Cisplatin, paclitaxel; CT: Carboplatin taxol; EBRT: External beam radiotherapy 
Raffaella G (2018) Tumoral Necrosis Factor (TNF) mRNA gene expression in relation to Vascular Endothelial Growth Factor (VEGF) and chemokines mRNA gene expression in tumoral microenvironment of endometrial cancer versus normal endometrium: Preliminary results

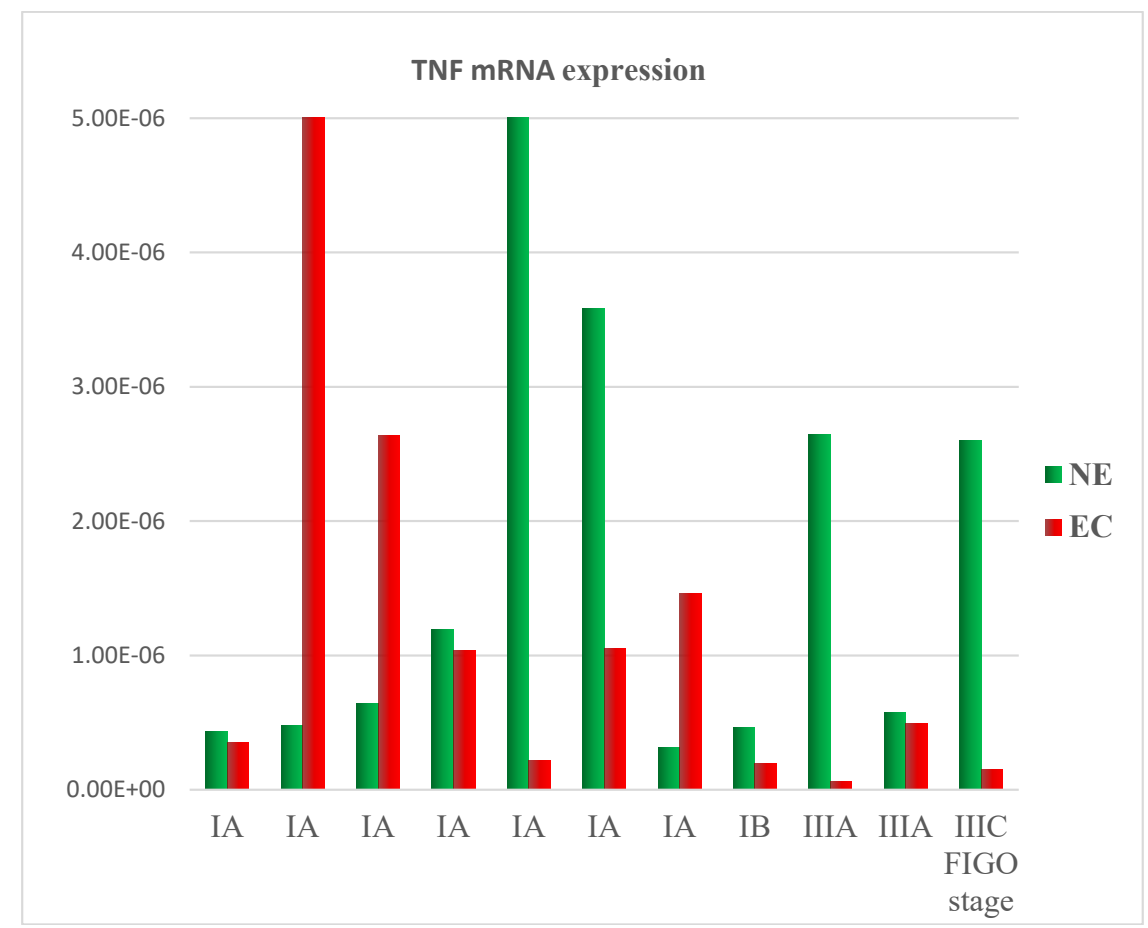

Figure 1. Tumor Necrosis Factor (TNF) mRNA expression in tissue samples from surgical speciment. In microenvironment of endometrial cancer samples (EC) compared with normal endometrium counterpart (NE), TNF mRNA was down-regulated in $73 \%$ of cases

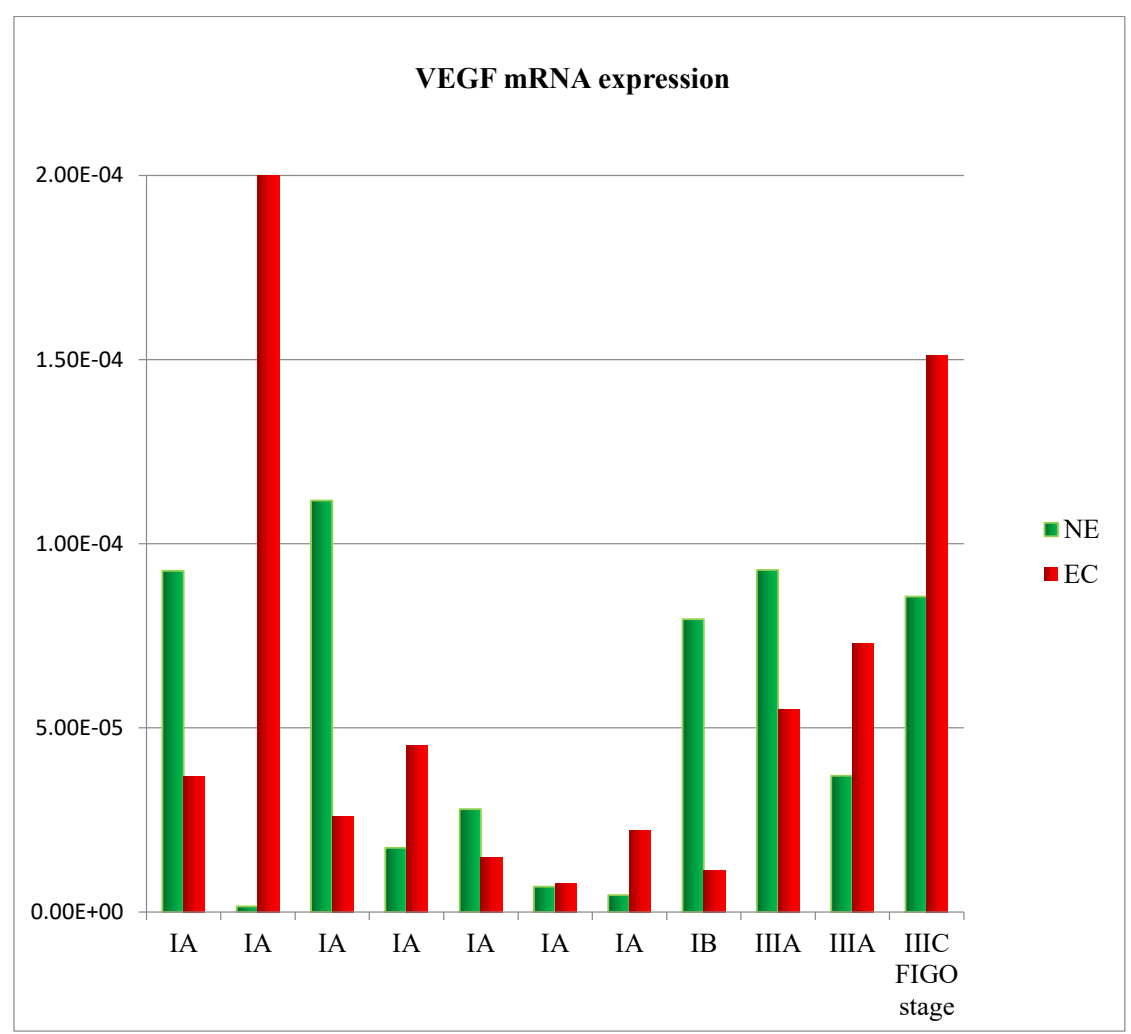

Figure 2. Vascular Endothelial Growth Factor (VEGF) mRNA expression in tissue samples from surgical speciment. In microenvironment of endometrial cancer samples (EC) compared with normal endometrium counterpart (NE), VEGF mRNA was down-regulated in $55 \%$ of cases 
Raffaella G (2018) Tumoral Necrosis Factor (TNF) mRNA gene expression in relation to Vascular Endothelial Growth Factor (VEGF) and chemokines mRNA gene expression in tumoral microenvironment of endometrial cancer versus normal endometrium: Preliminary results

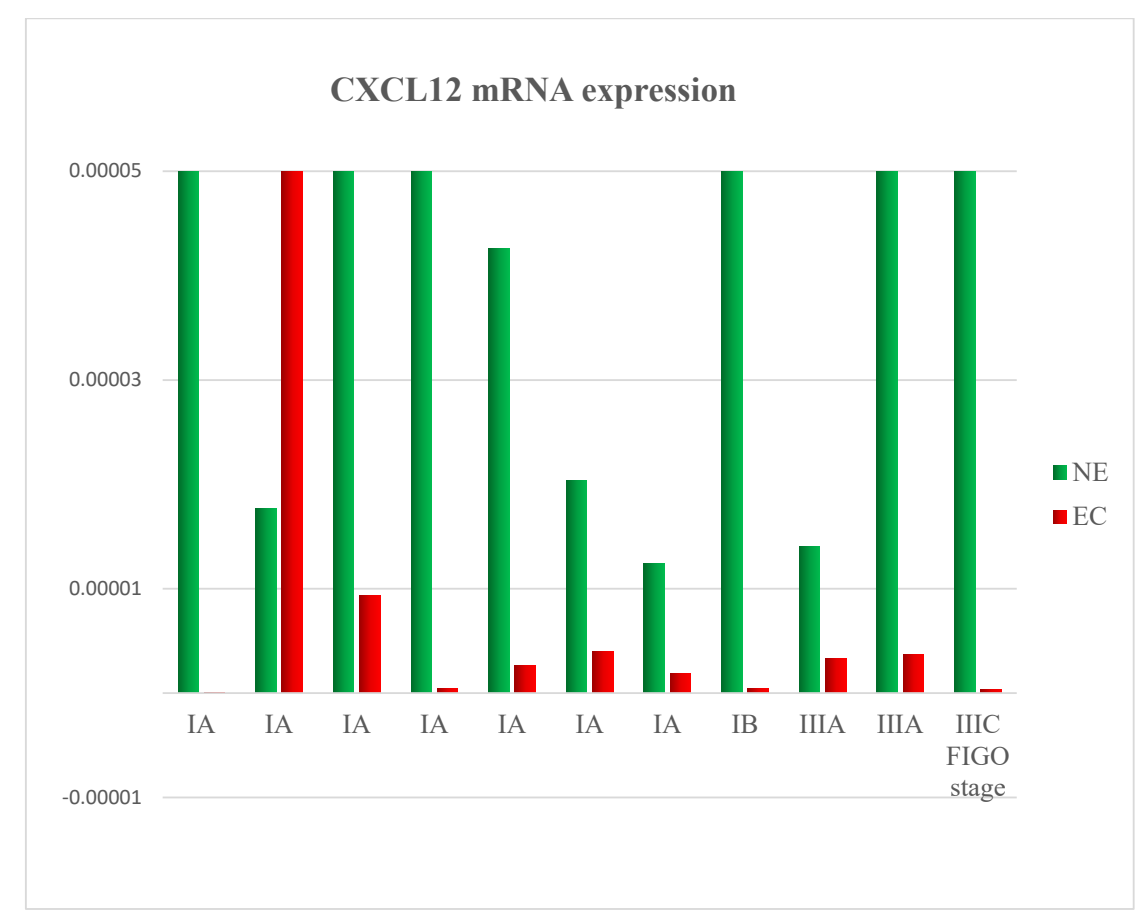

Figure 3. CXCL12 mRNA expression in tissue samples from surgical speciment. In microenvironment of endometrial cancer samples (EC) compared with normal endometrium counterpart (NE), CXCL12 mRNA was down-regulated in $91 \%$ of cases

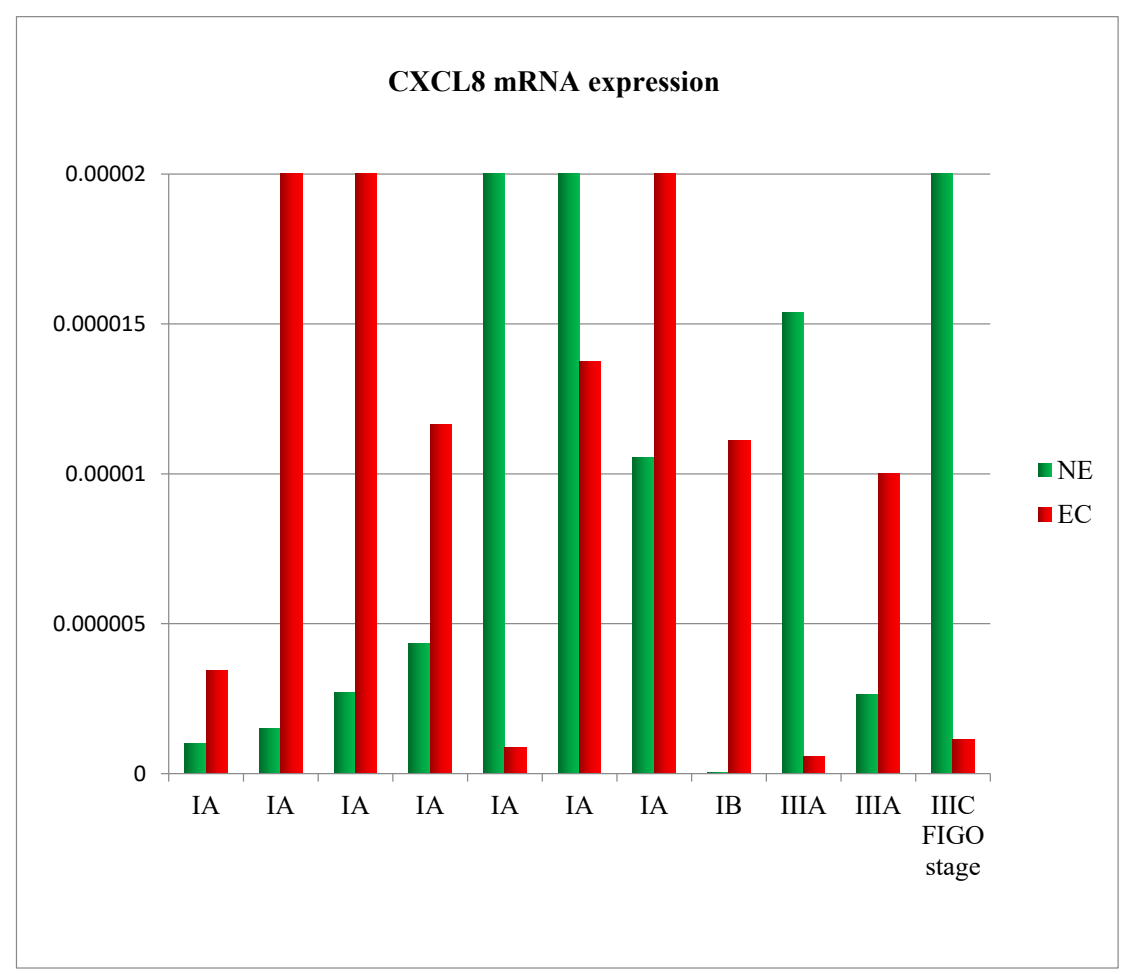

Figure 4. CXCL8 mRNA expression in tissue samples from surgical speciment. In microenvironment of endometrial cancer samples (EC) compared with normal endometrium counterpart (NE), CXCL8 mRNA was down-regulated in $64 \%$ of cases 
Raffaella G (2018) Tumoral Necrosis Factor (TNF) mRNA gene expression in relation to Vascular Endothelial Growth Factor (VEGF) and chemokines mRNA gene expression in tumoral microenvironment of endometrial cancer versus normal endometrium: Preliminary results

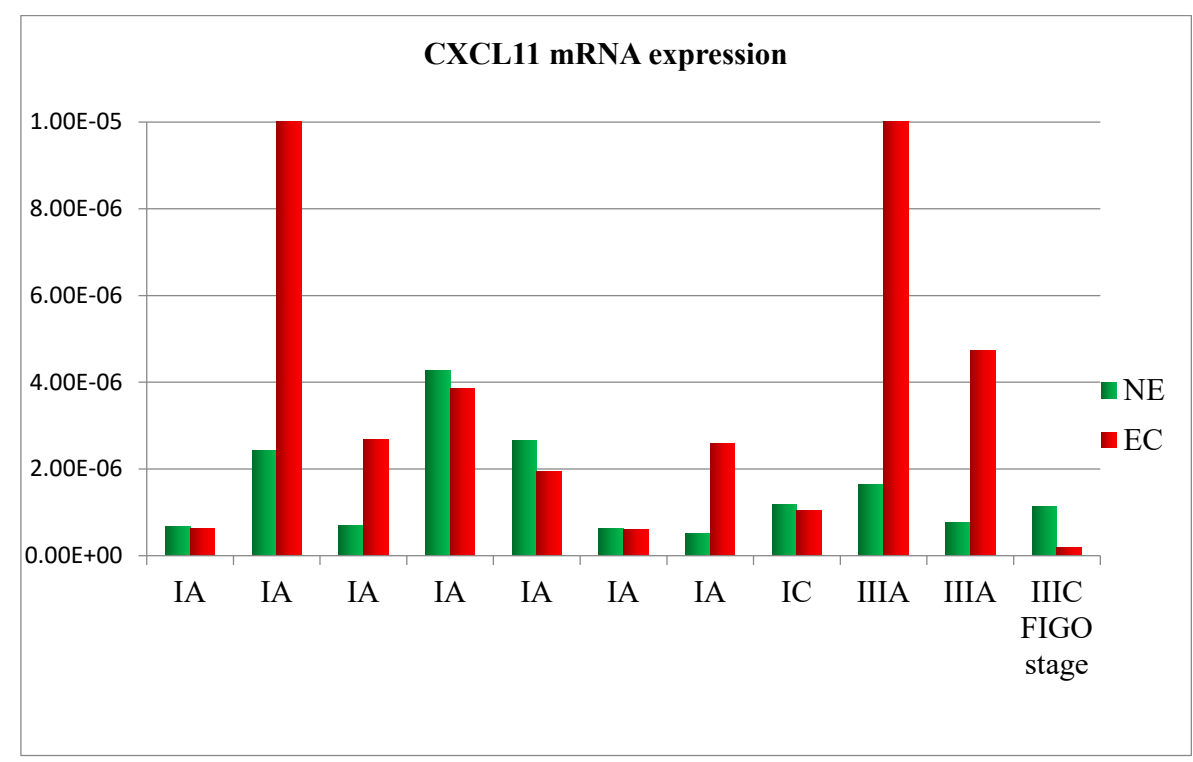

Figure 5. CXCL11 mRNA expression in tissue samples from surgical speciment. In microenvironment of endometrial cancer samples (EC) compared with normal endometrium counterpart (NE), CXCL11 mRNA was down-regulated in $54 \%$ of cases

Understanding the tumour microenvironment behaviors and how it affects tumour cells could represent an attractive therapeutic target. The results displayed in this preliminary study open new sceneries for further researches, identifying in which subpopulation of tumoral microenvironment this proteins mediator is over-expressed. We will expect from a further analysis on a greater sample size the definitive and more significant results.

\section{Conflicts of interest}

The authors declare no conflicts of interest.

\section{References}

1. Diez-Ruiz A, Tilz GP, Zangerle R, Baier-Bitterlich G, Wachter H, et al. (1995) Soluble receptors for tumour necrosis factor in clinical laboratory diagnosis. Eur $J$ Haematol 54: 1-8. [Crossref]

2. Manna SK, Aggarwal BB (2000) All-trans-retinoic acid upregulates TNF receptors and potentiates TNF-induced activation of nuclear factors- kappaB, activated protein-1 and apoptosis in human lung cancer cells. Oncogene 19: 2110-2119. [Crossref]

3. Balkwill F (2002) Tumor necrosis factor or tumor promoting factor? Cytokine Growth Factor Rev 13: 135-141. [Crossref]

4. Haider S, Knofler M (2009) Human tumour necrosis factor: physiological and pathological roles in placenta and endometrium. Placenta 30: 111-123. [Crossref]

5. Tabibzadeh S, Satyaswaroop PG, von Wolff M, Strowitzki T (1999) Regulation of TNF-alpha mRNA expression in endometrial cells by TNF-alpha and by oestrogen withdrawal. Mol Hum Reprod 5: 1141-1149. [Crossref]

6. Shaarawy M, bdel-Aziz O (1992) Serum tumour necrosis factor alpha levels in benign and malignant lesions of the endometrium in postmenopausal women. A preliminary study. Acta Oncol 31: 417-420. [Crossref]

7. Chopra V, Dinh TV, Hannigan EV (1997) Serum levels of interleukins, growth factors and angiogenin in patients with endometrial cancer. J Cancer Res Clin Oncol 123: 167172. [Crossref]

8. Dossus L, Becker S, Rinaldi S, Lukanova A, Tjønneland A, et al. (2011) Tumor necrosis factor (TNF)- $\alpha$, soluble TNF receptors and endometrial cancer risk: the EPIC study. Int J Cancer 129: 2032-2037. [Crossref]

9. Lin Y, Huang R, Chen L, Li S, Shi Q, et al. (2004) Identification of interleukin-8 as estrogen receptor regulated factor involved in breast cancer invasion and angiogenesis by protein arrays. Int $J$ Cancer 109: 507-515. [Crossref]

10. Schadendorf D, Moller A, Algermissen B, Worm M, Sticherling M, et al. (1993) IL-8 produced by human malignant melanoma cells in vitro is an essential autocrine growth factor. J Immunol 151: 2667-2675. [Crossref]
11. Yao PL, Lin YC, Wang CH, Huang YC, Liao WY, et al. (2005) Autocrine and paracrine regulation of interleukin-8 expression in lung cancer cells. Am J Respir Cell Mol Biol 32: 540-547. [Crossref]

12. Curiel TJ, Coukos G, Zou L, Alvarez X, Cheng P, et al. (2004) Specific recruitment of regulatory $\mathrm{T}$ cells in ovarian carcinoma fosters immune privilege and predicts reduced survival. Nat Med 10: 942-949. [Crossref]

13. Porcile C, Bajetto A, Barbero S, Pirani P, Schettini G (2004) CXCR4 activation induces epidermal growth factor receptor transactivation in an ovarian cancer cell line. Ann NY Acad Sci 1030: 162-169. [Crossref]

14. Kryczek I, Lange A, Mottram P, Alvarez X, Cheng P, et al. (2005) CXCL12 and vascular endothelial growth factor synergistically induce neoangiogenesis in human ovarian cancers. Cancer Res 65: 465-472. [Crossref]

15. Kulbe H, Thompson R, Wilson JL, Robinson S, Hagemann T, et al. (2007) The inflammatory cytokine tumor necrosis factor-alpha generates an autocrine tumour promoting network in epithelial ovarian cancer cells. Cancer Res 67: 585-592. [Crossref]

16. Kryczek I, Wei S, Keller E, Liu R, Zou W (2007) Stroma-derived factor (SDF-1/ CXCL12) and human tumor pathogenesis. Am J Physiol Cell Physiol 292: C987-995. [Crossref]

17. Strieter RM, Polverini PJ, Kunkel SL, Arenberg DA, Burdick MD, et al. (1995) The functional role of the ELR motif in CXC chemokine-mediated angiogenesis. $J$ Biol Chem 270: 27348-27357. [Crossref]

18. Moore BB, Arenberg DA, Addison CL (2005) Growth of epithelial ovarian cancer cells Cell Mol Immunol 2: 365-372.

19. Rosenkilde MM, Schwartz TW (2004) The chemokine system -- a major regulator of angiogenesis in health and disease. APMIS 112: 481-495. [Crossref]

20. Strieter RM, Burdick MD, Mestas J, Gomperts B, Keane MP, et al. (2006) Cancer CXC chemokine networks and tumour angiogenesis. Eur J Cancer 42: 768-778. [Crossref]

21. Salcedo R, Wasserman K, Young HA, Grimm MC, Howard OM, et al. (1999) Vascular endothelial growth factor and basic fibroblast growth factor induce expression of CXCR4 on human endothelial cells: in vivo neovascularization induced by stromalderived factor-1alpha. Am J Pathol 154: 1125-1135. [Crossref]

Copyright: (C2018 Raffaella G. This is an open-access article distributed under the terms of the Creative Commons Attribution License, which permits unrestricted use, distribution, and reproduction in any medium, provided the original author and source are credited. 